\title{
Developmental Trajectories of the Fronto-Temporal Lobes from Infancy to Early Adulthood in Healthy Individuals
}

\author{
Chiaki Tanaka $^{a}$ Mie Matsui $^{b}$ Akiko Uematsu ${ }^{b}$ Kyo Noguchic Toshio Miyawaki ${ }^{a}$ \\ Departments of a Pediatrics, ${ }^{b}$ Psychology and ${ }^{c}$ Radiology, Graduate School of Medicine and Pharmaceutical \\ Sciences, University of Toyama, Toyama, Japan
}

\section{Key Words}

Magnetic resonance imaging $\cdot$ Neurodevelopment • Frontal lobe $\cdot$ Temporal lobe $\cdot$ Brain volume $\cdot$ Infant $\cdot$ Laterality $\cdot$ Sex differences $\cdot$ Gray matter $\cdot$ White matter

\begin{abstract}
Brain development during early life in healthy individuals is rapid and dynamic, indicating that this period plays a very important role in neural and functional development. The frontal and temporal lobes are known to play a particularly important role in cognition. The study of healthy frontal and temporal lobe development in children is therefore of considerable importance. A better understanding of how these brain regions develop could also aid in the diagnosis and treatment of neurodevelopmental disorders. Some developmental studies have used magnetic resonance imaging (MRI) to examine infant brains, but it remains the case that relatively little is known about cortical brain development in the first few years of life. In the present study we examined whole brain, temporal lobe and frontal lobe developmental trajectories from infancy to early adulthood in healthy individuals, considering gender and brain hemisphere differences. We performed a cross-sectional, longitudinal morphometric MRI study of 114 healthy individuals ( 54 females and 60 males) aged 1 month to 25 years old (mean age \pm SD 8.8 \pm 6.9 . We measured whole brain, temporal and frontal lobe gray matter (GM)/white matter (WM) volumes, following pre-
\end{abstract}

viously used protocols. There were significant non-linear age-related volume changes in all regions. Peak ages of whole brain, temporal lobe and frontal lobe development occurred around pre-adolescence (9-12 years old). GM volumes for all regions increased significantly as a function of age. Peak age was nevertheless lobe specific, with a pattern of earlier peak ages for females in both temporal and frontal lobes. Growth change in whole brain GM volume was larger in males than in females. However, GM volume growth changes for the temporal and frontal lobes showed a somewhat different pattern. GM volume for both temporal and frontal lobes showed a greater increase in females until around 5-6 years old, at which point this tendency reversed (GM volume changes in males became greater), with male GM volume increasing for a longer time than that of females. WM volume growth changes were similar across regions, all increasing rapidly until early childhood but slowing down thereafter. All regions displayed significant rightward volumetric asymmetry regardless of sex. Furthermore, the right temporal and frontal lobes showed a greater volumetric increase than the left for the first several years, with this tendency reversing at around 6 years of age. In addition, the left frontal and temporal lobes increased in volume for a longer period of time. Taken together, these findings indicated that brain developmental trajectories differ depending on brain region, sex and brain hemisphere. Gender-related factors such as sex hormones and functional laterality may affect brain development.

Copyright @ 2012 S. Karger AG, Basel

\section{KARGER}

Fax +4161306 1234

E-Mail karger@karger.ch

www.karger.com
(C) 2012 S. Karger AG, Basel

0378-5866/12/0346-0477\$38.00/0

Accessible online at:

www.karger.com/dne
Mie Matsui, $\mathrm{PhD}$

Department of Psychology, Graduate School of Medicine and Pharmaceutical Sciences University of Toyama, 2630 Sugitani

Toyama 930-0194 (Japan)

E-Mailmmatsui@las.u-toyama.ac.jp 


\section{Introduction}

Child development has been an important focus of attention in various fields, including education, psychology and pediatrics. Some studies have used magnetic resonance imaging (MRI) to examine structural brain development. MRI provides a non-invasive method to observe brain changes in living people during development. MRI thus enables researchers to study pediatric brain development, which could support theories and help answer questions related to child development [1].

Many MRI studies have found that human brain volumes change in a non-linear fashion with age [2-4]. Both cortical and subcortical gray matter (GM) volume change according to an inverted U-shape function, whereas white matter (WM) continues to increase in volume throughout life [2-4]. The frontal and temporal brain regions underlie such cognitive processes as executing functioning and language, which have been shown to develop with age [5]. Frontal and temporal lobe volumes gradually increase with age until around early adolescence $[2,6-8]$. Although the frontal and temporal lobes appear to share similar basic developmental paths, there are some differences $[3,6,9]$. Matsuzawa et al. [6] reported that frontal lobe volumes increase more rapidly than those of the temporal lobes, and that unlike the frontal lobes, the temporal lobes show greater GM than WM increases. In addition, the temporal lobes appear to reach maximal GM volume approximately 3-4 years later than the frontal lobes [3].

In addition to such regional differences between frontal and temporal lobes, some studies have noted sexual dimorphism in brain development $[2-4,10]$. These studies have found that GM volume peaks generally occur earlier for females than males. Indeed, Giedd et al. [3] reported that GM volumes in the frontal lobes increased during pre-adolescence, with a maximal size occurring at 12.1 years for males and 11.0 years for females, whereas GM in the temporal lobes reached a peak at 16.7 years for males and 16.2 years for females. Sowell et al. [4] examined GM in the temporal lobes, finding a sex difference such that females had larger volumes than males.

Hemispheric asymmetries in both frontal and temporal lobes have also been reported in several studies $[1,7$, 11]. The Brain Development Cooperative Group [1] reported that nearly every regional volume shows a leftward hemispheric asymmetry, particularly WM in the temporal lobes. In contrast to this report, some earlier studies have reported rightward hemispheric asymmetries for GM volumes of the temporal lobes $[7,12]$.
Table 1. Age distribution of cross-sectional samples

\begin{tabular}{lccc}
\hline Age, years & Male & Female & Total \\
\hline $0-1$ & 11 & 5 & 16 \\
$1-2$ & 7 & 6 & 13 \\
$2-4$ & 7 & 3 & 10 \\
$4-6$ & 4 & 4 & 8 \\
$6-8$ & 4 & 3 & 7 \\
$8-10$ & 3 & 9 & 12 \\
$10-12$ & 4 & 5 & 9 \\
$12-14$ & 4 & 3 & 7 \\
$14-16$ & 4 & 6 & 10 \\
$16-18$ & 5 & 3 & 8 \\
$18-20$ & 3 & 3 & 8 \\
$20-26$ & 4 & 4 & 114 \\
\hline Total & 60 & 54 & \\
\hline
\end{tabular}

Some of these brain development studies included infant data $[6,13]$, but it still remains that very little is known about cortical development in the first years of life. We previously used MRI to study healthy children aged 1 month to 10 years, finding growth spurts for the whole brain, frontal lobes and temporal lobes during the first 2 years after birth [6]. The present study further extended the age range into the $20 \mathrm{~s}$, examining whole brain, frontal lobe and temporal lobe volumes. We utilized both cross-sectional and longitudinal data to support the validity of the identified developmental trajectories. We hypothesized that GM development in infants through early adulthood would be non-linear as described previously, and that there would be a peak age for each regional volume around adolescence. We also predicted that there would be sex and laterality differences in developmental trajectories. Finally, we predicted that developmental trajectories based on cross-sectional data would be similar to those based on longitudinal data.

\section{Method}

\section{Participants}

MRI data were collected from 1998 to 2010. Participants included 114 healthy and normally developing Japanese (60 males and 54 females) from 1 month to 25 years old (mean monthly age $\pm \mathrm{SD}=106 \pm 83.15)$. Twenty of them had 2 scans (11 males and 9 females), and 5 of them had 3 scans ( 3 males and 2 females), the remainder having only 1 . Age and gender distributions for the age brackets are provided in table 1 and numbers and mean ages for the longitudinal scans are shown in table 2. Child participants included children of university hospital staff members and par- 
Table 2. Number of longitudinal scans per subject

\begin{tabular}{|c|c|c|c|c|c|c|}
\hline \multirow[t]{2}{*}{ Scan } & \multicolumn{2}{|l|}{ Male } & \multicolumn{2}{|l|}{ Female } & \multicolumn{2}{|l|}{ Total } \\
\hline & scans, $\mathrm{n}$ & $\begin{array}{l}\text { age at scan } \\
(\text { mean } \pm S D), \text { years }\end{array}$ & scans, $\mathrm{n}$ & $\begin{array}{l}\text { age at scan } \\
(\text { mean } \pm S D), \text { years }\end{array}$ & scans, $\mathrm{n}$ & $\begin{array}{l}\text { age at scan } \\
(\text { mean } \pm S D), \text { years }\end{array}$ \\
\hline $1 \mathrm{st}$ & 60 & $8.8 \pm 6.8$ & 54 & $9.5 \pm 6.5$ & 114 & $8.8 \pm 6.9$ \\
\hline $2 \mathrm{nd}$ & 11 & $8.8 \pm 6.8$ & 9 & $12.5 \pm 6.0$ & 20 & $10.4 \pm 6.6$ \\
\hline $3 \mathrm{rd}$ & 3 & $14.1 \pm 3.8$ & 2 & $16.3 \pm 5.2$ & 5 & $15.0 \pm 3.9$ \\
\hline
\end{tabular}

a
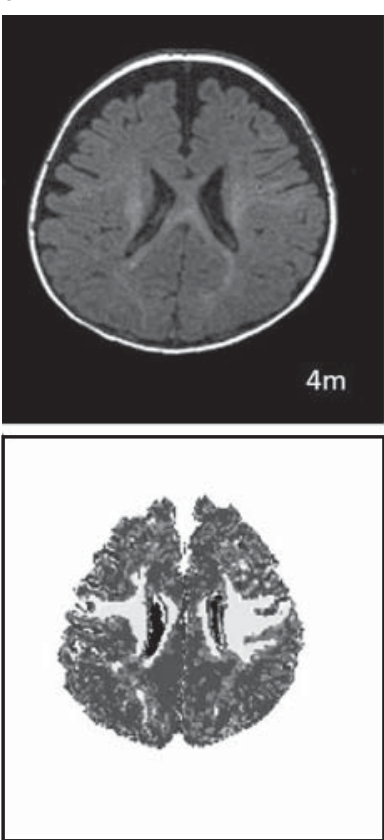

b
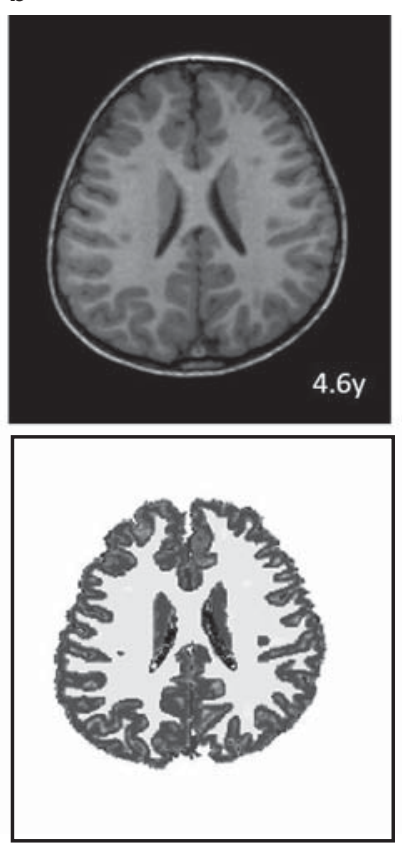
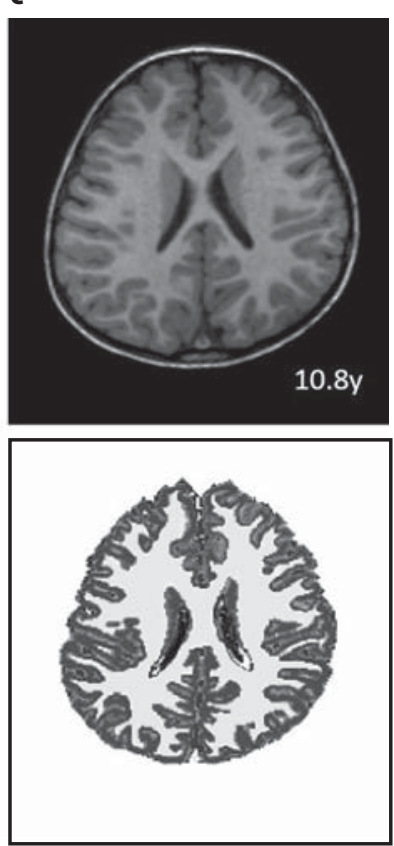

Fig. 1. Sample MRI of longitudinal T1weighted scans from 1 participant at 4 months (a), 4.6 (b) and 10.8 (c) years of age. Segmentation of the scan below each image: white $=\mathrm{WM}$; gray $=\mathrm{GM}$; black $=$ CSF .

ents who were attending a community class on raising children, or children attending school in the Kureha region in Toyama city. All children were born at full term (gestational ages between 37 and 41 weeks). Participants older than 18 years were recruited from the University of Toyama or were acquaintances of hospital staff. All participants were screened via an interview targeting health issues and were found to have no major health issues or abnormal neurological development. Nineteen children under 42 months of age were evaluated using the Bayley Scales of Infant Development, second edition (BSID-II). The mean mental development index was $97.1(\mathrm{SD}=11.5)$, and the mean psychomotor developmental index (PDI) was $97.7(\mathrm{SD}=10.5)$. Thirty children from 48 months to 16 years were evaluated using the Wechsler Pre-school and Primary Scale of Intelligence (WPPSI) or the Wechsler Intelligence Scale for Children, third edition (WISCIII). The mean IQ for this group was $109.6(\mathrm{SD}=13.0)$. Heights and weights were all in the normal range (males: height $119.4 \pm$ $40.2 \mathrm{~cm}$, weight $29.9 \pm 22.6 \mathrm{~kg}$, females: height $129.0 \pm 34.8 \mathrm{~cm}$, weight $33.3 \pm 17.1 \mathrm{~kg}$ ), and all participants were right-handed. After the purpose and all study procedures were fully explained, written informed consent was obtained from the participants and/or their parents (if the participants were not college students or adults). Forty-seven participants below 6 years old were sedated with Triclofos sodium syrup $(0.5-0.7 \mathrm{ml} / \mathrm{kg})$ before the scans. This drug was administered once only, and the study was discontinued for 1 child who did not fall asleep after the single dose was administered. This study was reviewed and approved by the Research and Ethics Committee at the University of Toyama.

\section{Image Acquisition}

T1-weighted axial images were obtained with a 1.5 T Magnetom Vision scanner (Siemens, Erlangen, Germany), using a fast low angle shot gradient refocused 3-dimensional sequence with the following parameters: echo time $(\mathrm{TE})=6 \mathrm{~ms}$, repetition time $(\mathrm{TR})=35 \mathrm{~ms}$, flip angle $=35^{\circ}$, nex $=1$, field of view $=256 \mathrm{~mm}$ and matrix size $=256 \times 256$. Entire scans were obtained in $15 \mathrm{~min}$. Slice thickness was $1.0 \mathrm{~mm}$ and 140-180 contiguous slices were obtained in each case. The same scanner was used for all participants. Figure 1 shows sample MRIs from one participant (longitudinal T1-weighted scans) at 4 months, 4.6 and 10.8 years old. 


\section{Image Analysis}

Images were transferred to a Linux workstation so that intracranial and total brain volumes could be obtained. Image processing was performed using Dr. View image analysis software (Asahi Kasei Joho System Co. Ltd., Tokyo, Japan). Intracranial volumes (ICVs) were manually traced based on Whitewell et al. [14]. This manual tracing preceded in axial view from superior to inferior, by drawing around the dura, excluding any bone marrow or any other non-brain tissue but including the superior sagittal sinus. The optic nerves were also excluded.

Whole, temporal and frontal brain volumes were measured based on Matsuzawa et al. [6]. Briefly, collection of data in the axial plane required neuroanatomic knowledge to separate the supratentorial from infratentorial compartments. For the whole brain, all supratentorial slices were analyzed and the infratentorial cerebral-spinal fluid (CSF) and associated tissue were excluded by placing a boundary around the posterior fossa on each slice. On inferior slices, frontal lobe borders were the interhemispheric fissure and cortical perimeter. Above the mammillary bodies, the posterior border was defined using a horizontal line from the most anterior extent of the sylvian fissure to the interhemispheric fissure. Tracings were continued in this fashion until the slice immediately preceding the splenium of the corpus callosum, where a new posterior border was defined using a horizontal line touching the most anterior part of the caudate nucleus. In addition, above all slices where the lateral ventricles were no longer visible, regions anterior to a line connecting the most medial and lateral points of the central sulcus were calculated as the frontal area. At the midbrain level, the posteromedial border of the temporal lobe was delineated by the pons and cerebellum. The sylvian fissure was used to separate the temporal lobe from adjacent frontal regions. The posterior boundary was defined by drawing a line extending from the contralateral cerebral peduncle to the anterior tip of the cerebellum. The sylvian fissure and the diencephalon structures served as the medial borders above the mammillary bodies. The posterior edge was formed using a horizontal line from the most posterior tip of the posterior fossa to the lateral perimeter. The slice preceding the splenium of the corpus callosum represented the superior extent of the temporal lobe tracings.

Registered and corrected volumes were segmented into GM, WM and CSF using an image-analyzing software, FSL, freely downloaded through http://www.fmrib.ox.ac.uk/fsl/.

\section{Regional Volumetric Measurement Reliability}

Inter-rater reliability was examined using a sample of 10 randomly selected brain scans analyzed by two raters (C.T. and K.I.). Intra-class correlations for total cerebral volumes ranged from 0.87 to 0.99 . Those for the frontal lobes ranged from 0.82 to 0.99 , and those for the temporal lobes ranged from 0.90 to 0.99 . Intrarater reliability was also examined in the same 20 scans analyzed by one of these raters (C.T.), and the correlations for total cerebral, frontal and temporal lobe volumes ranged from 0.94 to 0.97 . The rater (C.T.) then completed the analysis on the remaining scans.

\section{Statistical Analysis}

SPSS 19.0 was used to perform regression analyses of linear, quadratic and cubic models that were used to determine whether age (in months) was related to volume changes of the whole brain, frontal lobes and temporal lobes, dividing the sample into the whole group, a female group and a male group. $\mathrm{R}^{2}$ values were used to decide which linear or non-linear models best characterized the development of each region. From the estimated models, peak ages and the local maximal volumes of each region were calculated for the whole, female and male groups, if possible. In addition, the differentiation (= growth change) in each month was calculated from the best-characterized model and graphed from 1 month until the peak age.

To examine laterality, right and left volumes were expressed as a laterality index as follows:

$$
\text { Laterality index }=(\text { left }- \text { right }) /(\text { left }+ \text { right })
$$

Index values can, in principle, range from 0.0 (symmetrical) to \pm 1.0 (asymmetrical). A one-sample $t$ test was performed for each subsample (testing against the reference value of 0.00 ). In addition, a linear regression analysis was performed to detect any relationship between laterality and age.

In addition to the raw measured volumes, we also examined the volumes adjusted by ICV, using the following equation [15]:

$$
\text { Adjusted volume }=\text { raw volume }-b^{*}(\mathrm{ICV}-\text { mean ICV }) \text {, }
$$

where $b$ is the slope of a regression line of region of interest volume on ICV. Mean ICV was calculated separately for each year of age below 15 because of large year-to-year volume increases. Mean ICV was calculated as a single mean for participants above the age of 16 .

\section{Results}

Scatter plots representing whole brain, frontal lobe and temporal lobe development are illustrated in figure 2 , with estimated curves.

\section{Estimated Curves for the Whole Brain, Temporal Lobes and Frontal Lobes}

Regression analyses revealed that age (in months) was significantly related to volume changes in the whole brain, temporal lobe, frontal lobe and their GM and WM volumes for all of the linear, quadratic and cubic models (all $\mathrm{p}$ values $<0.001$ ). The $\mathrm{R}^{2}$ values were highest for the cubic model for every region (table 3 ): whole brain $[\mathrm{F}(3,110)=84.9, \mathrm{p}<0.001]$, temporal lobe $[\mathrm{F}(3,110)=$ $87.3, \mathrm{p}<0.001]$, frontal lobe $[\mathrm{F}(3,110)=84.7, \mathrm{p}<0.001]$, whole brain $\mathrm{GM}[\mathrm{F}(3,104)=37.8, \mathrm{p}<0.001]$, temporal lobe $\mathrm{GM}[\mathrm{F}(3,104)=61.4, \mathrm{p}<0.001]$, frontal lobe $\mathrm{GM}$ $[\mathrm{F}(3,104)=44.4, \mathrm{p}<0.001]$, whole brain $\mathrm{WM}[\mathrm{F}(3,104)$ $=98.5, \mathrm{p}<0.001]$, temporal lobe $\mathrm{WM}[\mathrm{F}(3,104)=66.8$, $\mathrm{p}<0.001]$ and frontal lobe WM $[\mathrm{F}(3,104)=89.0$, $\mathrm{p}<0.001]$. These results were consistent after adjustment and division by sex and brain hemisphere. Because the results were consistent after adjustment by ICV, table 3 shows only the results from the raw data.

\section{Peak Ages and Growth Changes}

Peak ages calculated using the estimated cubic models are shown in table 3 . The female group reached its local 


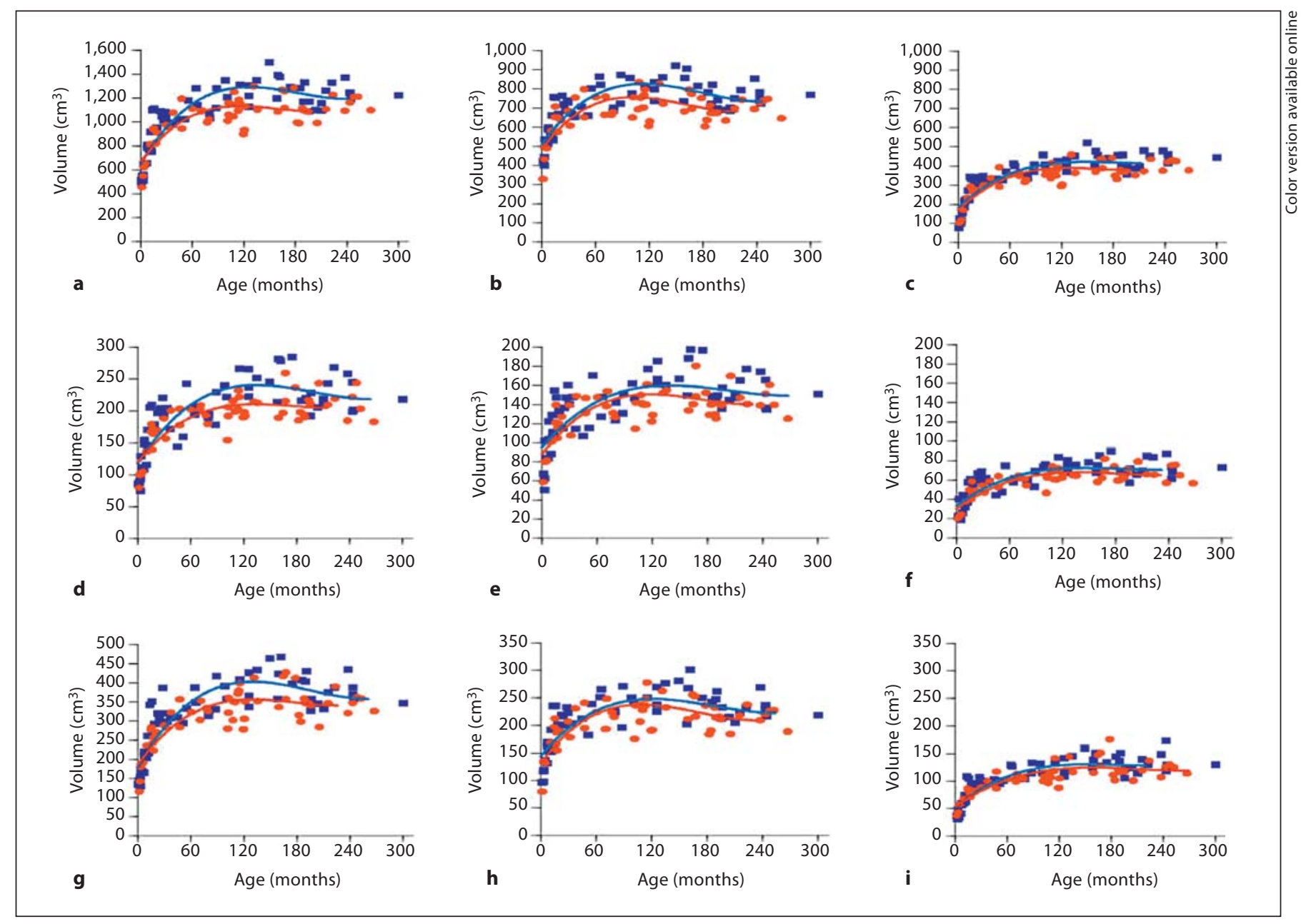

Fig. 2. Individual data points and best-fitting cross-sectional age curves for males and females separately for whole brain (a), whole brain GM (b), whole brain WM (c), temporal lobe (d), temporal lobe GM (e), temporal lobe WM (f), frontal lobe (g), frontal lobe GM (h) and frontal lobe WM (i). Females are shown with open circles (red in the online version) and males are shown with filled squares (blue in the online version).

maximal volume earlier than the male group for all regions but the frontal lobe, peak ages of which were the same for both sexes. In addition, the left temporal volume reached its peak around 1.5 years later than the right temporal volume, although the latter tended to be greater than the former. These trends could be seen even after adjustment. The pattern of earlier peak size in females also could be seen for all GM volumes, including the frontal lobes.

Figure 3 depicts growth changes for the whole brain, temporal lobes, frontal lobes and corresponding GM/ $\mathrm{WM}$, all of which showed a rapid volume increase in the first few years from birth, regardless of sex.

Developmental Trajectories of the Fronto-Temporal Lobes
Whole brain volumes in males tended to show greater changes than those of females until around 10 years old. In addition, whole brain GM volume showed a larger increase as well as a greater degree of volume change in males, regardless of age (fig. 3a, b). WM also increased to a greater extent in males for the first few years after birth (fig. 3c).

Temporal lobe volume changes were greater in males across all ages (fig. 3d). Female GM volumes in this region increased to a greater extent than in males until around 5 years of age, but this tendency then reversed such that changes in males became greater, with male temporal GM volumes increasing for longer than those of females (fig. 3e). On the other hand, no sex difference is shown in the temporal WM growth-change graph (fig. 3f). In terms 
Table 3. Best-fitting developmental trajectory model with peak ages

\begin{tabular}{|c|c|c|c|c|}
\hline Brain region & $\begin{array}{l}\text { Best-fitting } \\
\text { model }\end{array}$ & Sex & $\mathrm{R}^{2}$ & $\begin{array}{l}\text { Age of } \\
\text { peak, years }\end{array}$ \\
\hline \multirow[t]{3}{*}{ Whole brain GM } & \multirow[t]{3}{*}{ cubic } & male & 0.68 & 9.2 \\
\hline & & female & 0.49 & 8.5 \\
\hline & & total & 0.53 & 9.0 \\
\hline \multirow[t]{3}{*}{ Temporal lobe GM } & \multirow[t]{3}{*}{ cubic } & male & 0.58 & 11.6 \\
\hline & & female & 0.53 & 9.9 \\
\hline & & total & 0.52 & 10.7 \\
\hline \multirow[t]{3}{*}{ Frontal lobe GM } & \multirow[t]{3}{*}{ cubic } & male & 0.66 & 10.1 \\
\hline & & female & 0.53 & 9.2 \\
\hline & & total & 0.57 & 9.6 \\
\hline \multirow[t]{3}{*}{ Whole brain WM } & \multirow[t]{3}{*}{ cubic } & male & 0.82 & n.a. \\
\hline & & female & 0.72 & n.a. \\
\hline & & total & 0.74 & n.a. \\
\hline \multirow[t]{3}{*}{ Temporal lobe WM } & \multirow[t]{3}{*}{ cubic } & male & 0.69 & n.a. \\
\hline & & female & 0.69 & n.a. \\
\hline & & total & 0.66 & n.a. \\
\hline \multirow[t]{3}{*}{ Frontal lobe WM } & \multirow[t]{3}{*}{ cubic } & male & 0.80 & n.a. \\
\hline & & female & 0.66 & n.a. \\
\hline & & total & 0.72 & n.a. \\
\hline \multirow[t]{3}{*}{ Whole brain } & \multirow[t]{3}{*}{ cubic } & male & 0.80 & 10.6 \\
\hline & & female & 0.68 & 9.7 \\
\hline & & total & 0.70 & 10.4 \\
\hline \multirow[t]{3}{*}{ Left whole brain } & \multirow[t]{3}{*}{ cubic } & male & 0.81 & 10.6 \\
\hline & & female & 0.68 & 9.5 \\
\hline & & total & 0.70 & 10.4 \\
\hline \multirow[t]{3}{*}{ Right whole brain } & \multirow[t]{3}{*}{ cubic } & male & 0.79 & 10.5 \\
\hline & & female & 0.54 & 10.4 \\
\hline & & total & 0.64 & 10.7 \\
\hline \multirow[t]{3}{*}{ Temporal lobe } & \multirow[t]{3}{*}{ cubic } & male & 0.69 & 11.3 \\
\hline & & female & 0.65 & 11.1 \\
\hline & & total & 0.63 & 11.4 \\
\hline \multirow[t]{3}{*}{ Left temporal lobe } & \multirow[t]{3}{*}{ cubic } & male & 0.69 & 12.6 \\
\hline & & female & 0.67 & 11.9 \\
\hline & & total & 0.64 & 12.7 \\
\hline \multirow[t]{3}{*}{ Right temporal lobe } & \multirow[t]{3}{*}{ cubic } & male & 0.66 & 10.8 \\
\hline & & female & 0.60 & 10.8 \\
\hline & & total & 0.59 & 11.0 \\
\hline Frontal lobe & cubic & male & 0.77 & 10.9 \\
\hline & & female & 0.68 & 10.9 \\
\hline & & total & 0.70 & 11.0 \\
\hline Left frontal lobe & cubic & male & 0.79 & 11.3 \\
\hline & & female & 0.68 & 10.9 \\
\hline & & total & 0.71 & 11.4 \\
\hline Right frontal lobe & cubic & male & 0.77 & 10.6 \\
\hline & & female & 0.66 & 10.8 \\
\hline & & total & 0.70 & 10.7 \\
\hline
\end{tabular}

of hemispheric differences, the right temporal lobe showed a greater volumetric increase than the left for the first several years from birth. However, this tendency reversed at around 6 years of age, and the left temporal lobe increased in volume for longer than the right (fig. $4 \mathrm{a}, \mathrm{b}$ ).

As was the case for the temporal lobes, frontal lobe volume change was greater in males across ages (fig. 3g). For WM changes, males showed a greater increase than females across all ages (fig. 3i). GM volume changes were also similar to those observed for the temporal lobe. GM volume increased to a greater extent in females than in males, until around 5 years old, but this tendency then reversed and male temporal GM volume increased for longer than that of females (fig. 3h). The right frontal lobe showed a greater increase in volume than the left for the first several years, but this tendency reversed at around 6 years old, and the left frontal lobe showed a longer increase (fig. 4c, d). These results held true after adjustments by ICV.

\section{Laterality}

All regions displayed significant rightward volumetric asymmetry in both males and females, which remained after adjustment: whole brain laterality index for males: mean $\pm \mathrm{SD}=-0.011 \pm 0.007, \mathrm{t}(59)=-12.50, \mathrm{p}<0.001$ laterality index for females: mean $=-0.011 \pm 0.006$, $\mathrm{t}(53)=-13.98, \mathrm{p}<0.001$, temporal lobe laterality index for males: mean $\pm \mathrm{SD}=-0.028 \pm 0.037, \mathrm{t}(59)=-5.93, \mathrm{p}<$ 0.001 ; laterality index for females: mean $=-0.032 \pm$ $0.033, \mathrm{t}(53)=-6.97, \mathrm{p}<0.001$, frontal lobe laterality index for males: mean $\pm \mathrm{SD}=-0.012 \pm 0.031, \mathrm{t}(59)=-3.15$, $\mathrm{p}=0.003$; laterality index for females: mean $=-0.019 \pm$ $0.025, \mathrm{t}(53)=-5.44, \mathrm{p}<0.001$.

Figure 5 shows the relationship between laterality index and age. A linear regression analysis of age and laterality index indicated that only the female laterality index of the temporal lobe significantly changed according to age, from negative to 0 (rightward to symmetrical) as a function of age, $F(1,52)=7.61, p=0.008$. Laterality index did not significantly change as a function of age for the whole brain or the frontal lobes: whole brain $\mathrm{F}(1,112)=$ $0.473, \mathrm{p}=0.493$, frontal lobe $\mathrm{F}(1,112)=0.394, \mathrm{p}=0.531$. The same result was obtained after adjustment by ICV. For the temporal lobes of both sexes, $\mathrm{F}(1,58)=4.539, \mathrm{p}=$ 0.037 for males, and $\mathrm{F}(1,52)=6.743, \mathrm{p}=0.012$ for females.

\section{Longitudinal Model}

Figure 6 shows the longitudinal model on scatter plots of cross-sectional data. The trajectory for each region was almost the same shape as the best-fitting models. Peak ages were similar to those of cross-sectional models. 

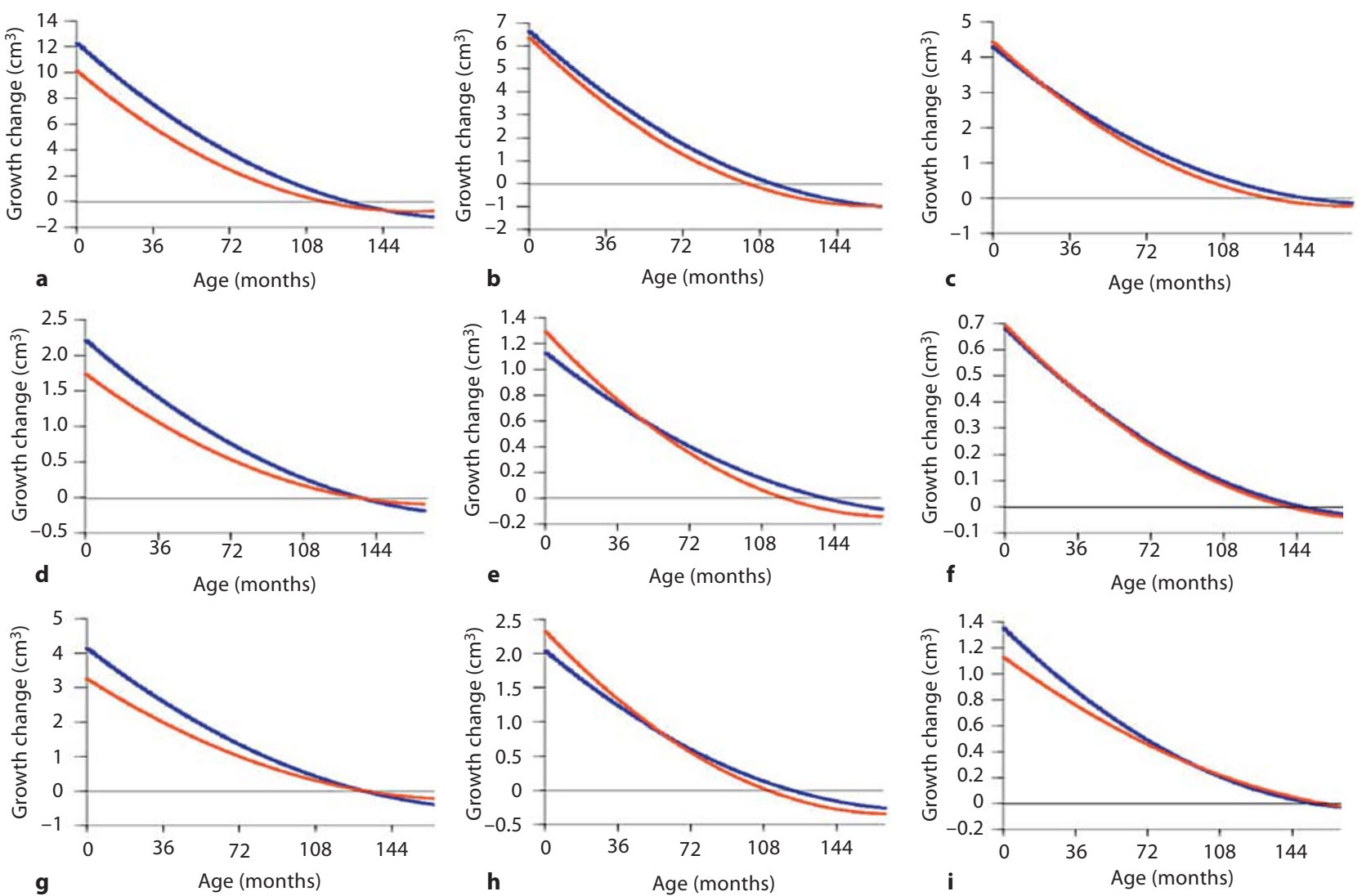

Fig. 3. Rate of monthly growth change for whole brain (a), whole brain GM (b), whole brain WM (c), temporal lobe (d), temporal lobe GM (e), temporal lobe WM (f), frontal lobe (g), frontal lobe GM (h) and frontal lobe WM (i). Positive values represent increasing volume and negative values loss of volume. Grey curves (red in the online version) show females and black curves (blue in the online version) show males.

Fig. 4. Best-fitting curve for temporal lobe volume for left and right hemispheres (a), rate of monthly growth for right and left temporal lobe (b), best-fitting curve for frontal lobe (c) and growth change for frontal lobe (d). Black lines (blue in the online version) show left hemisphere and grey lines (green in the online version) show right hemisphere.
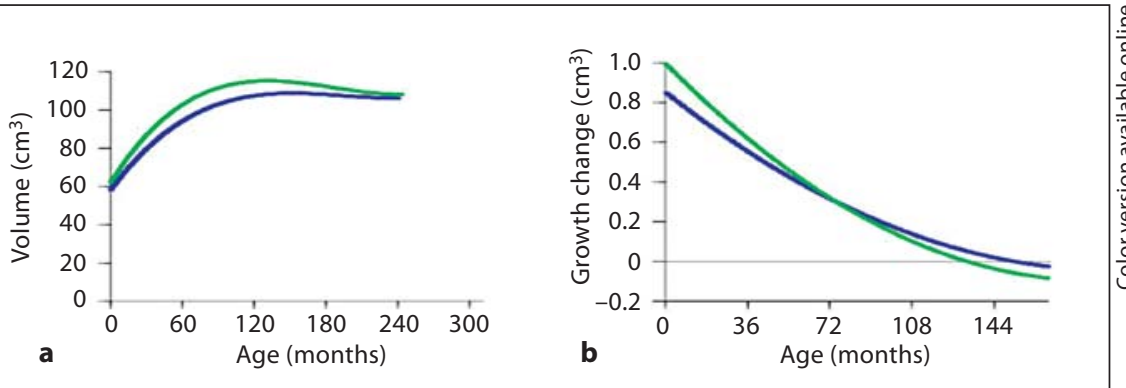
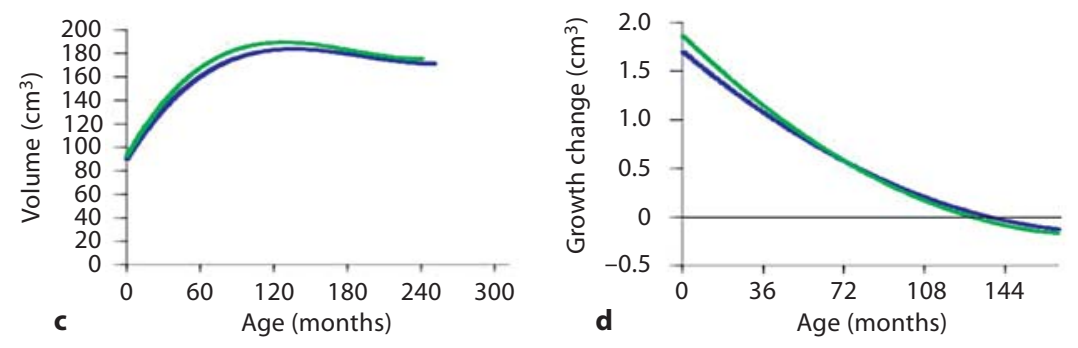


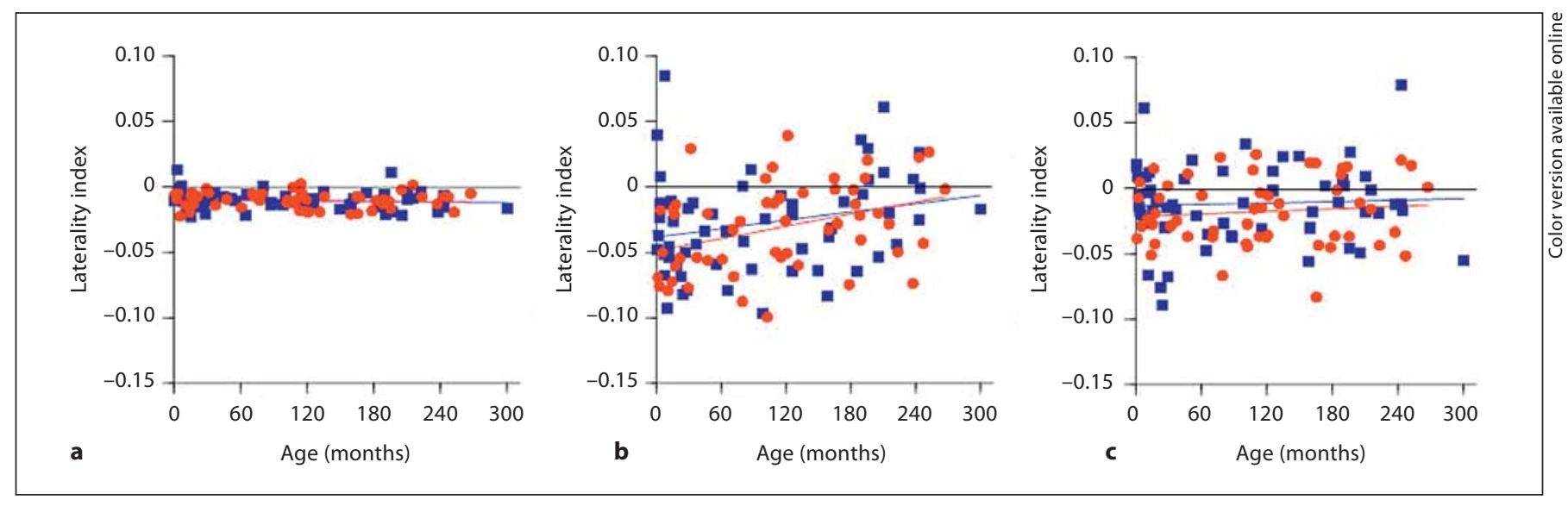

Fig. 5. The relationship between laterality index and age for whole brain (a), temporal lobe (b) and frontal lobe (c). Open circles (red in the online version) show females and filled squares (blue in the online version) show males.

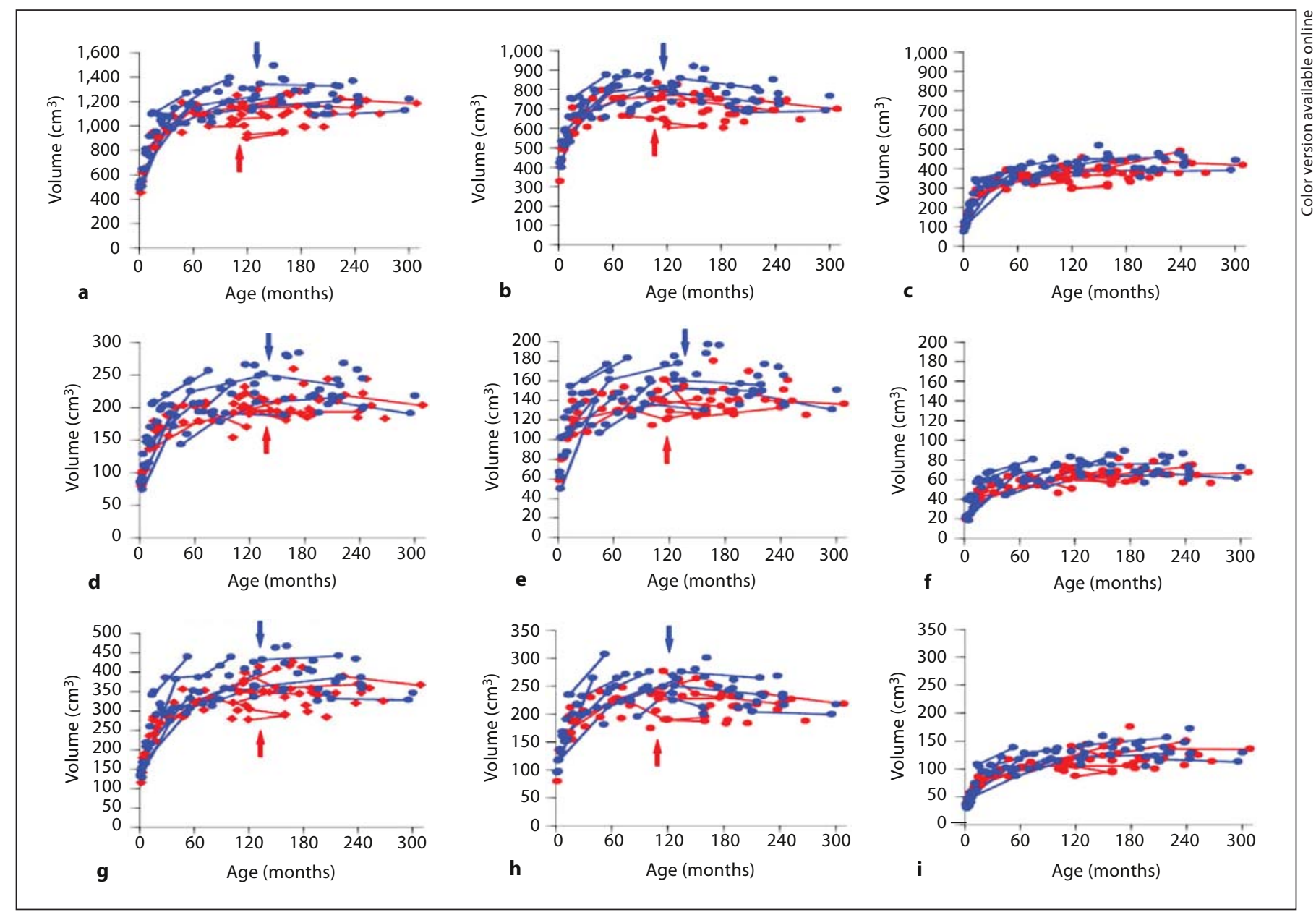

Fig. 6. Scatter plot of longitudinal measurements on the cross-sectional measurements for whole brain (a), whole brain GM (b), whole brain WM (c), temporal lobe (d), temporal lobe GM (e), temporal lobe WM (f), frontal lobe (g), frontal lobe GM (h) and frontal lobe WM (i). The arrows show the peak ages for each region calculated using the best-fitting cubic models. Grey dots (red in the online version) show females and black dots (blue in the online version) show males. 


\section{Discussion}

Whole brain, frontal lobe and temporal lobe volumes exhibited significant age-related changes from infancy to early adulthood, even after adjustment by ICV. The estimated developmental trajectory models were best characterized as cubic for all of the studied brain regions regardless of sex and the specific hemisphere in question. The age at which peak volume was reached came around 1 year earlier in females for all studied regions. These results are consistent with those of previous studies $[2,3]$. Nevertheless, peak ages were somewhat different across these studies, including the present one. Frontal GM volume peaks in an earlier study [3] were 11.0 years for females and 12.1 years for males, whereas in the present study frontal GM peaked at 9.2 in females and 10.1 in males, a result similar to that of Lenroot et al. [2] ( 9.5 years in females and 10.5 years in males). Temporal GM volume peaks in the present study were 9.9 years in females and 11.6 years in males. Again, this is similar to the report of Lenroot et al. [2] (10 years in females and 11 years in males), while Giedd et al. [3] reported peaks of 16.7 years in females and 16.5 years in males. Such peak age differences could have occurred due to differences in sample size, age ranges studied, statistical methods [2] and race/ethnicity. In addition, it also should be noted that the present study included infant data, with such steep growth changes likely to have a great influence on our analysis. Besides, we also computed peak ages with our sample excluding infants $(\mathrm{n}=$ 85), obtaining a temporal GM volume peak age of 14.9 years, and a frontal GM volume peak age of 11.5 years. This result closely resembles earlier studies that did not include infants $[1,2,3,7,8]$. Therefore, the present study expands upon these prior studies by examining brain volume developmental curves and peaks along the entire developmental spectrum from infancy to adulthood $[1,2,3,7,8]$.

WM volume increased rapidly for all regions studied until early childhood, with increases becoming more gradual at around 10 years old. This finding is consistent with previous work [6]. Some aging studies suggest that WM volume seems to reach a peak in the mid-forties [9, 16, 17]. Bartzokis et al. [9] determined that WM volume continues to increase into the fifth decade of life, suggesting an increase in myelination and/or enhanced interconnectivity of lobes. Sowell et al. [17] noted that increases in WM volume with age suggest that a relative decline in GM density until around age 40 is related to an increase in cerebral myelination.

Developmental Trajectories of the Fronto-Temporal Lobes
GM volumes also increased rapidly for all regions studied here, but unlike WM volumes these reached a peak at approximately 9-11 years of age. Such peak ages were lobe specific, although a pattern of earlier peak age in females was seen for both temporal and frontal lobes. These results are consistent with previous studies $[2,3]$. For instance, we found that in the temporal lobes peak GM volume occurred at 9.9 for females and 11.6 years for males, whereas in the frontal lobes the peak ages were 9.2 for females and 10.1 years for males. Thus, temporal lobe volumes increased more slowly than frontal volumes, particularly in males, which is again consistent with previous studies [2, 3]. A review by Lenroot and Giedd [18] concluded that GM volume developmental trajectories would follow regionally specific patterns: those regions sub-serving primary functions such as motor and sensory systems would mature earliest, whereas higher-order areas involved in integration of those primary functions would be expected to mature later. Indeed, Bartzokis et al. [9] reported that temporal WM volume reaches a peak later than for the frontal lobes. This makes sense given that the temporal lobes contain the superior temporal gyrus/sulcus, which integrates memory, audio-visual input and object recognition functions [19-21]. Gogtay et al. [22] also noted that cortical GM development appears to follow the functional maturation sequence, with the primary sensorimotor cortices along with frontal and occipital poles maturing first, with the superior temporal cortex, which contains association areas that integrate information from several sensory modalities, maturing last [22].

In addition to these patterns, the right temporal lobe tended to evidence a greater volume than the left, particularly in males regardless of age. This replicates our previous study [6]. Jack et al. [12] evaluated the right-left asymmetry of temporal lobe volumes in adults, concluding that both the anterior temporal lobe and hippocampal formation are significantly larger in the right hemisphere than in the left. Such asymmetries are already identifiable in neonates and infants [23], suggesting that temporal lobe asymmetries precede the development of speech and language.

We also found higher growth rates for the right temporal and frontal lobes as compared to their left counterparts for the first several years of life, but this tendency reverses after around 6 years. As compared to the right hemisphere, peak age of left hemisphere volume occurred later by about 1-2 years for the temporal lobe, and about $0.5-0.8$ years for the frontal lobe. This finding may be explained by the fact that speech and language are sub-

Dev Neurosci 2012;34:477-487 
served by the temporal lobes. According to recent diffusion tensor imaging studies, frontal-temporal connections (cingulum, uncinate fasciculus, superior longitudinal fasciculus) have been shown to mature slowly during childhood and adolescence [24-26]. The superior longitudinal fasciculus connecting Broca's area in the frontal lobe with Wernicke's area in the temporal is involved in various language and intelligence tasks [27].

It should be noted that language dominance and handedness are not perfectly correlated. Right-handers (but not left-handers) typically show dominance of the left hemisphere for speech and language comprehension [28]: approximately $97 \%$ of right-handers show left hemisphere speech and language localization. Certain language skills such as vocabulary and overall linguistic proficiency can continue to develop into later adulthood [29]. Therefore, language skill may progress by leaps and bounds at around 2 years of age when a child begins to speak and show another developmental peak in later childhood when the child starts to study at school. This hypothesis is consistent with our finding of a growth rate reversal in favor of the left hemisphere at around 6 years of age, with the left hemisphere increasing in volume for a longer period than the right.

Developmental trajectories derived from longitudinal data closely resembled best-fitting models based on crosssectional data, with peak ages similar across the two data sources. However, individual comparisons between plots do reveal considerable variability. Large sample sizes and/ or longitudinal designs are needed if general patterns are to be found among the substantial individual differences seen in cortical structural development [7]. In addition,
Lenroot et al. [2] noted that the combination of crosssectional and longitudinal data provides a powerful tool for analyzing brain development. The present results should therefore be replicated using a more extensive pool of longitudinal data provided by healthy individuals.

A limitation of this study should be noted. Volume changes per se cannot directly reveal the development of neural networks, which tells us how functional localization and neural circuits develop over time. Combinations of volumetric data, psycho-developmental tests and/or fractional anisotropy values/fiber tractography through diffusion tensor imaging could help to clarify how specific aspects of neural development occur.

In summary, this predominantly cross-sectional study demonstrates how whole brain, temporal lobe and frontal lobe volumes develop from infancy to early adulthood in healthy individuals. Cubic models most accurately characterized the developmental trajectories in these regions, but specific volume increases and decreases differed depending on sex, brain region and hemisphere in question. Factors that affect brain development would be expected to have a differential impact based on these variables.

\section{Acknowledgements}

This study was supported by a Grant-in-Aid for Scientific Research (B) 20330141 and (A) 21243040 from the Japan Society for the Promotion of Science (JSPS) and JSPS Asian Core Program. We thank Megumi M. Tanaka and Satoshi Uda for their assistance with this work.

\section{References}

1 Brain Development Cooperative Group: Total and regional brain volumes in a population-based normative sample from 4 to 18 years: The NIH MRI study of normal brain development. Cereb Cortex 2012;22:1-12.

2 Lenroot RK, Gogtay N, Greenstein DK, Wells EM, Wallace GL, Clasen LS, Blumenthal JD, Lerch J, Zijdenbos AP, Evans AC Thompson PM, Giedd JN: Sexual dimorphism of brain developmental trajectories during childhood and adolescence. Neuroimage 2007;36:1065-1073.

> Giedd JN, Blumenthal J, Jeffries NO, Castellanos FX, Liu H, Zijdenbos A, Paus T, Evans AC, Rapoport JL: Brain development during childhood and adolescence: a longitudinal MRI study. Nat Neurosci 1999;2:861-863.
-4 Sowell ER, Trauner DA, Gamst A, Jernigan TL: Development of cortical and subcortical brain structures in childhood and adolescence: a structural MRI study. Dev Med Child Neurol 2002;44:4-16.

5 Paus T: Mapping brain maturation and cognitive development during adolescence. Trends Cogn Sci 2005;9:60-68.

-6 Matsuzawa J, Matsui M, Konishi T, Noguchi K, Gur RC, Bilker W, Miyawaki T: Age-related volumetric changes of brain gray and white matter in healthy infants and children. Cereb Cortex 2001;11:335-342.

7 Giedd JN, Vaituzis AC, Hamburger SD, Lange N, Rajapakse JC, Kaysen D, Vauss YC, Rapoport JL: Quantitative MRI of the temporal lobe, amygdala, and hippocampus in normal human development: ages 4-18 years. J Comp Neurol 1996;366:223-230.
-8 Shaw P, Kabani NJ, Lerch JP, Eckstrand K, Lenroot R, Gogtay N, Greenstein D, Clasen L, Evans A, Rapoport JL, Giedd JN, Wise SP: Neurodevelopmental trajectories of the human cerebral cortex. J Neurosci 2008;28: 3586-3594.

9 Bartzokis G, Beckson M, Lu PH, Nuechterlein $\mathrm{KH}$, Edwards N, Mintz J: Age-related changes in frontal and temporal lobe volumes in men: a magnetic resonance imaging study. Arch Gen Psychiatry 2001;58:461465.

10 Cowell PE, Turetsky BI, Gur RC, Grossman RI, Shtasel DL, Gur RE: Sex differences in aging of the human frontal and temporal lobes. J Neurosci 1994;14:4748-4755.

11 Toga AW, Thompson PM: Mapping brain asymmetry. Nat Rev Neurosci 2003;4:37-48. 
12 Jack CR Jr, Twomey CK, Zinsmeister AR, Sharbrough FW, Petersen RC, Cascino GD: Anterior temporal lobes and hippocampal formations: normative volumetric measurements from MR images in young adults. Radiology 1989;172:549-554.

13 Gilmore JH, Shi F, Woolson SL, Knickmeyer RC, Short SJ, Lin W, Zhu H, Hamer RM, Styner M, Shen D: Longitudinal development of cortical and subcortical gray matter from birth to 2 years. Cereb Cortex 2012;22: 2478-2485.

14 Whitwell JL, Crum WR, Watt HC, Fox NC: Normalization of cerebral volumes by use of intracranial volume: implications for longitudinal quantitative MR imaging. AJNR Am J Neuroradiol 2001;22:1483-1489.

15 Raz N, Lindenberger U, Rodrigue KM, Kennedy KM, Head D, Williamson A, Dahle C, Gerstorf D, Acker JD: Regional brain changes in aging healthy adults: general trends, individual differences and modifiers. Cereb Cortex 2005; 15:1676-1689.

-16 Bartzokis G, Cummings JL, Sultzer D, Henderson VW, Nuechterlein KH, Mintz J: White matter structural integrity in healthy aging adults and patients with Alzheimer's disease: a magnetic resonance imaging study. Arch Neurol 2003;60:393-398.
Sowell ER, Peterson BS, Thompson PM, Welcome SE, Henkenius AL, Toga AW: Mapping cortical change across the human life span. Nat Neurosci 2003;6:309-315.

18 Lenroot RK, Giedd JN: Brain development in children and adolescents: insights from anatomical magnetic resonance imaging. Neurosci Biobehav Rev 2006;30:718-729.

19 Martin A, Chao LL: Semantic memory and the brain: structure and processes. Curr Opin Neurobiol 2001;11:194-201.

20 Mesulam MM: From sensation to cognition. Brain 1998;121:1013-1052.

21 Calvert GA: Crossmodal processing in the human brain: insights from functional neuroimaging studies. Cereb Cortex 2001;11: $1110-1123$

22 Gogtay N, Giedd JN, Lusk L, Hayashi KM, Greenstein D, Vaituzis AC, Nugent TF 3rd, Herman DH, Clasen LS, Toga AW, Rapoport JL, Thompson PM: Dynamic mapping of human cortical development during childhood through early adulthood. Proc Natl Acad Sci USA 2004;101:8174-8179.

23 Utsunomiya H, Takano K, Okazaki M, Mitsudome A: Development of the temporal lobe in infants and children: analysis by MRbased volumetry. AJNR Am J Neuroradiol 1999;20:717-723.
24 Hasan KM, Kamali A, Abid H, Kramer LA, Fletcher JM, Ewing-Cobbs L: Quantification of the spatiotemporal microstructural organization of the human brain association, projection and commissural pathways across the lifespan using diffusion tensor tractography. Brain Struct Funct 2010;214:361-373.

25 Kochunov P, Williamson DE, Lancaster J, Fox P, Cornell J, Blangero J, Glahn DC: Fractional anisotropy of water diffusion in cerebral white matter across the lifespan. Neurobiol Aging 2012;33:9-20.

26 Westlye LT, Walhovd KB, Dale AM, Bjornerud A, Due-Tonnessen P, Engvig A, Grydeland $\mathrm{H}$, Tamnes CK, Ostby Y, Fjell AM: Lifespan changes of the human brain white matter: diffusion tensor imaging (DTI) and volumetry. Cereb Cortex 2010;20:20552068.

27 Catani M, Allin MP, Husain M, Pugliese L, Mesulam MM, Murray RM, Jones DK: Symmetries in human brain language pathways correlate with verbal recall. Proc Natl Acad Sci USA 2007;104:17163-17168.

28 Witelson SF: Cognitive neuroanatomy: a new era. Neurology 1992;42:709-713.

29 Ravid D, Tolchinsky L: Developing linguistic literacy: a comprehensive model. J Child Lang 2002;29:417-447, discussion 453-417, 466-474. 